\title{
The Reform of Moral Education in Japan*
}

\author{
Lee-Min Lai \\ Taiwan Shoufu University, Taiwan \\ Wen-San Huang, Kuang-Li Han \\ National Kaohsiung Normal University, Taiwan
}

\begin{abstract}
This research aims at doing the investigations of the moral education curriculum applied in Japanese primary and secondary schools. for the research method, interviews with scholars and school teachers were conducted, meanwhile the responses of subjects were further analyzed. The curriculum about moral courses are the analysises from The soul notebook and Our own moral. Based on the study result, due to Japanese morality curriculum has become an official moral education, and it can become the core of school education and enhance the attention of comprehension to cultivate morality. Therefore, the valuable concept of "thinking morality" or "discussion morality" can be raised. Moreover, through the changes of the current trendency in Japan, the "modern topics", should be contained and connected with the international issues of the morality curriculum. Furthermore, the content limited of the international issues in the academic year should be considered to be expanded more. At last, suggestions for the further research are proposed on the basis of the findings of the present study.
\end{abstract}

Keywords: Japanese education reform, moral education, special subject --- morality, international issues

\section{Introduction}

Adolescence is a critical stage of human beings, and it has many special mental characteristics and developmental tasks. Since the adolescence is to a great extent caused by growth patterns, several characteristics of the growth patterns in adolescence contribute to and make it a very complex process. As young adolescents mature physically, they grow in body size and develop more motor skills; there is also a concurrent growth in moral development. Therefore, morality is also one of the important characteristics in the adolescence.

If you ask passers-by on the street about what they consider to constitute a "good person", the answer is nothing but a mixture of virtues, emotions, good habits, and behaviors. The traditional view of morality favored in 19th century Europe, and values we call "moral" were presumed to be provided by God. However, Freud suggested that the reverse is true: "The newborn," he argued, "is naturally without concern for the welfare of others. Moral values, if they are present at all, must be cultivated after birth" (Huang, 2001).

Thus, whether educators accept the fact or not, it is impossible for schools to stay out of moral education. Taiwan's society in the 21 st century is not only a knowledge management society, but also a society of moral

\footnotetext{
* The fist edition was published in 12th Anniversary Conference of the Asia-Pacific Network for Moral Education (APNME), named The Discourse and Analysis of the Moral Education Curriculum in Japan and Related International Issues.

Lee-Min LAI, Ph.D., Assistant Professor, Department Early Childhood, Taiwan Shoufu University.

Wen-San Huang, Ph.D., Professor, Department of Education National Kaohsiung Normal University.

Kuang-Li Han, Doctoral Candidate, Department of Education National Kaohsiung Normal University.
} 
re-structure. Therefore, all adolescents must learn new knowledge along with good morality during this critical period. Teachers must integrate different items of the moral areas and develop programs to foster moral virtues of the students at all schools. The purpose of this study is to help administrators and teachers to understand more of Japan's moral curriculum content, thereby improving moral instruction and designing effective moral teaching methods, upon which the moral development of adolescents in Taiwan are based.

Japan's Education Base Act says:

Education shall aim for the full development of personality and strive to nurture the citizens, sound in mind and body, who are imbued with the qualities necessary for those who from a peaceful and democratic state and society. The completion of personality and the formation of the foundation of national education are moral. In addition, the cultivation of morality is the mission of moral education in school education. On March, 27th, 2015, the policy of school education was modified.

Based on this, this research aims to discuss Japanese special subject, "morality", in the curriculum guideline of the elementary school, and middle school. There are four main structures: (1) the matter about self; (2) the matter about interaction with others; (3) the matter about interaction with groups and society; (4) the matter about interaction with nature and super nature.

In addition, the modern issue that the researcher mentions corresponds to the sub-textbook "our morality", which was issued by Ministry of Education, Culture, Sports Science and Technology of Japan. The contents of modern issue include "environment", "understanding of different cultures", "life ethics", "regional society", and "information". This research aims to analyze how Japanese experts or teachers in the elementary and middle school put moral education into practice, and the research result would serve as the reference for the twelve-year compulsory education in Taiwan.

\section{Literature Analysis}

According to the research aim above, literature analysis concerning Japan's moral education curriculum are provided below:

The learning guideline of the modern subject of morality of the elementary school states:

The curriculum includes:

(1) For first and second graders: Get close to people and culture from other countries;

(2) For third and fourth graders: In addition to getting close to people and culture, students should take care and pay attention to people and cultures from other countries;

(3) For fifth and sixth graders: In addition to understanding people and culture from other countries, and keeping self-awareness, students have to make efforts to do international work of goodwill.

Curriculum for the three groups is further described in details as follows:

(1) For first and second graders: First of all, when guiding, attention should be paid to the cultures of other countries from the surroundings, books, food, clothing, housing, and transportation. Children can communicate and make contact with other countries through sports and matters of daily life, being kind to people of other countries while cherishing the culture of their own country, and acknowledging the advantages of exotic cultures. Thereafter, communicate with people from other countries to deepen understandings of each other's culture, know more about other countries, and make efforts to communicate with other countries with the thoughts of cherishing the closeness. 
(2) For third and fourth graders: At this stage, focus is made to the interaction between our own country and various countries. Secondly, understanding and care of the diverse cultures and their characteristics beside our country are enhanced gradually.

At the time of guidance, it is the goal for the children, in their various living and learning, to care about and pay more attention to people and cultures of other countries. It is important to look at the commonalities and differences between the cultures of the other countries and the culture of your own country while keeping the focus on the local culture.

Based on this, identifying and feeling all kinds of advantages and then, understanding that people of other countries lead lives following their own cultures. Deeper understanding and more care of the cultures of other countries are achieved. It is important for students to get close to this matter. Furthermore, by focusing on the distance, we can attach importance to the culture of our own country and pay attention to the connection to the cultures of other countries.

(3) For fifth and sixth graders: They are "keeping the heart for cherishing of foreigners and cultures, maintaining the conscious of being a Japanese, and striving for international goodwill", children can have extensive contacts with the news media from everyday life, or from their learning in the social sciences and foreign language activities in the development of social cognitive abilities, for example, such as the national flags and national anthems of our own country and other countries. Under the mutual understanding and respect of each other, children can further deepen their care and understanding of other countries, and also make contact with people, art and culture of other countries in their various learning. Therefore, children's increase their chances of learning from other countries.

Researchers believe that children should be cultivated with the knowledge of their own country while they are young, so that they know and understand their own country's culture, thereby identifying their own country. Thereafter, they will learn about the culture of other countries, from which they can acknowledge the commonality between the countries, as well as the differences between them. A viewpoint of acceptance and respect will be formed, as it is very important to emphasize the internationalization in education with the trend of the society nowadays.

According to the above, at the time of guidance, not only can we deepen international understanding through the interactions between various cultures, but also fostering the importance of cultivating an international goodwill attitude. At the same time, it is important to promote further understanding of people in other countries, the cultural tradition they follow, and the lifestyle they are proud of.

Furthermore, with the conscious and proud as Japanese, understanding of the traditions and cultures of his own country is continuously deepened. A respectful attitude is employed to consider his own capability and to promote connections with people from other county. The pursue to an attitude of fostering international goodwill starts from promoting exchange activities.

In summary, from the section on morals of the "Learning and Guidance Essentials" of the primary schools, the focus on "international understanding, international contribution" is to understand the people and culture of other countries, make efforts on international goodwill, while keeping the conscious as Japanese.

The learning guideline of the modern subject of morality of the middle school states:

There are four main parts in the moral section of "Learning and Guidance Essentials" of the Japanese secondary schools: 
1. Mainly self-related (autonomy, self-discipline, freedom and responsibility, moderation, restraint, aspiration, individuality, hope and courage, self-abnegation and strong will, truth exploration, and creation);

2. Concerns for other people's interaction, including care, appreciation, courtesy, friendship, trust, mutual understanding, and tolerance;

3. Concerns for groups and social interaction related matters, such as respect for the law, public morality, justice, fairness, social justice, social participation, public spirit, hard work, family love, fulfillment of family life, better school life, enrichment of group life, local tradition and cultural respect, attitudes of love of locals, respect of traditions and cultures of own country, patriotic attitude, international understanding, and international contribution;

4. Interactions related to natures and super-natures, respect for life, love of nature, beliefs in awe and appreciation, and joy of survival.

In the middle school period, interactive learning starts with other subjects not long after enrollment to increase interest and concern for countries around the world. With the advancement of grades, there is a lot of knowledge gained from various fields in the knowledge-based society, starting from the political and economic cultures of each foreign country. Information can now be obtained instantly, which increases the chances of using various ways for interactive experiences with other countries around the world, thereby a deeper understanding of our own traditional culture and different cultures is achieved with more interactions made between everyone in the world.

First of all at the time of guidance, like Japan, there are good and established traditions behind other countries. For example, there are national flags and national anthems for other countries. Active respect for each other is cultivated in the learning, while cherishing and understanding the unique cultures other countries are proud of. At this time, understanding tradition and culture is based on the common goal of being human. Emphasis on the belief in the understanding and respect of everyone and different cultures of other countries is crucial. Furthermore, there are deeper thoughts on the necessity of respect and coexistence of the others who share different cultural diversity and values.

In the future, particularly for the middle school students surviving under the interdependence of globalization, the goal is to move toward the broader world and to reflect the ability of survival in the international community. This ability is necessary. Therefore, at the same time, the adaptability to respond to changes in society and implementing one's role and responsibility in the international community as recognized Japanese is required.

Further, the ideal of embracing world peace and contributing to human development is cherished and to be achieved with efforts. In order to achieve this ideal, no prejudice and difference should be held for the different feelings, thinking, and living habits for each country, and they should be treated fairly; this is not the moral value pursued by only the Japanese.

Among the four modern issues are mentioned above, the most important one is the international understanding and international contribution. It mainly lies in keeping Japanese self-awareness and respecting other countries with international visions, as well as getting along with people around the world peacefully.

\section{The Related Research of Modern Subject}

The content of curriculum includes: (1) the internalization of Japanese education: Japan has strongly promoted overseas study, and emphasized the education of oversea students and Japanese students. It hopes to 
put the co-feeling of culture into practice and realizes education of globalization and multi-culture. (2) the moral education of post war, subject of morality, and the international understanding: Japanese researcher Shigeki Kaizuka pointed out in 2016 that the Japanese government accepted the suggestion on internalization of education from the Provisional Education Board in 1984, and modified the learning guidelines in 1989 to individually describe the "international understanding and international contribution" for the middle school. This enhances the exploitation of international understanding and improvement of the guidance.

However, there is always a gap between an ideal and actual implementation. In the Integrated Moral Education Scheme promoted by Tokyo National University of Fine Arts and Music in 2012, the internal survey reveals that the percentage of the teachers to "emphasize on international understanding and international contribution" in the moral education is $6.0 \%$ in the elementary school and $6.3 \%$ in the middle school. However, on the other items of the moral education, such as "empathy and kindness", there is a percentage of $80.4 \%$ in the elementary school and $82.8 \%$ in the middle school; while "respect for life" is $64.2 \%$ in the elementary school and $74.9 \%$ in the middle school (Tokyo Gakugei University, 2012; Kaizuka, 2016).

From the above, it is apparent that "emphasize on international understanding and international contribution" is not significant in the international issues of the process of moral education in Japan to nurture an internationalized Japanese. According to Shigeki Kaizuka in 2016, the so-called abstract and conceptual world man is non-existent; it is the love for the human beings that cultivated the right patriotism.

For the above, Mayumi Nishino (1994) thought that the idea is "Movement is made with the center on the consciousness as Japanese and the understanding of the Japanese cultures, in contrast to the international understanding, the theme is to make contribution to the human beings of the world". It thus can be seen that "essentially, the international understanding education is in the context of patriotism".

Further, Shigeki Kaizuka (2016) also mentioned the description made by Junichiro Yasuzawa the education inspector in "Being a Japanese in the World" concerning the morals as "a quest to the guide for the human in the international society as a subjective Japanese". Based on this , Junichiro Yasuzawa further asserts the following: (1) To nurture a person who mutually respect as human beings no matter which nationality, and deepen the understanding of and respectful attitude toward Japan as well as the exotic cultures and foreign; (2) A consideration for the overall happiness of the entire human beings on the international standpoint, and cultivating the self who contribute to the world peace and human welfares; and (3) Emphasizing on the necessity of keeping the self-awareness as Japanese in the world and cultivating the self who could make contribution based on the world peace and human welfares.

Japan should keep Japanese self-awareness and the sense of identity about Japanese culture. Moreover, it has to understand the international affairs and make international contributions. There are three points in particular: (a) the understanding for human beings; (b) The understanding for culture; and (c) the understanding for real world. The Japanese international responsibility: In the interviews, the interviewees mentioned the topic of 2020 Tokyo Olympic Games. Nowadays, they have emphasis on the meaning of Tokyo Olympic Games that is taking place and convey to the children, where they learn how to communicate with the people around the world, continuously keeping an eye on modern issues, and engage in international understanding and goodwill.

Takashi OTSU (2010) mentioned that the civic education of Japan comprises of the three subjects including moral, social science, and integrated learning. In integrated learning, many Japanese teachers adopt the topics, such as the relevance between the international understanding, individual moral education, and worldwide civic education. This is because a good citizen has the duty to become a world citizen. In Part Four 
of the moral section of the "Learning and Guidance Essentials", it indicates to respect foreign and foreign cultures and be friendly to the worldwide countries as Japanese. Takashi OTSU (2010) emphasied that the Japan textbooks have a description on what is international contribution: We should be aware of the global civic education in the 21th century and aim to become the world citizen by working hard to solve the global problems.

Takashi OTSU (2010) mentioned that the practice in Japan is to understanding feelings of other people is the emphasis to understand the cultures of others; therefore, it is necessary to understand different cultures (trans-culturally). Shishuke Shishido (2016) indicated that the connection between people in the affected area of the East Japan Great Earthquake retains a "empathic dependence", which converts from passive empathy to active empathy.

Further, Hiroyuki Akahori (2016) indicated that on the item of "in the item of 'goodwill", a topic is built on the 2020 Tokyo Olympic Games where children can feel the other countries, finding stuffs from other countries in their daily lives, introduce to salutation of the world, and plan for the motivation of making communication. Consideration items are added in Grade 3 and 4, which are related to apply the potential continuous developments for the modern society.

(4) Special subject, morality-the adjustment of developing the improvement of moral education: Faced with the change of curriculum, surely raise Japanese self-awareness, be a member in the whole world, make international contribution and equip with Japanese literacy.

Ohara Ryuichi (2016a) indicated in the content of the special subject, morals, of the first and second school year to respond to improving the enhancement on moral education that regarding being close to each person and culture of other countries, the changes made to the specially allocated countries, can be found. In Showa Year 33, "it is natural for citizens to help each other; foreign should be treated without prejudice but with kindness and warm-heartedness. In Showa Year 43, it was changed to "Keeping the kindness from the bottom of the hearts to help each other with warm heart". In Showa Year 52, the item on help each other with warm culture of other countries is deleted and restored in Heisei Year 27.

Ohara Ryuichi (2016a) also indicated that Olympic Games were held in Showa Year 33 and Heisei Year 27 , more foreign will be accepted and there will be more sharing of lives with the foreign. The international situation is subtle then and today, the position and standpoint of Japan in the world is under attention. The Japaneses, under this, realize the implementation to become the international person standing with the world while maintaining the self-awareness as Japanese, is more pursuing. Moreover, Mayumi Nishino (2013) believed that the eves that the "international understanding" project of Japan should pursue for better understanding and exploit together with people having various viewpoints.

Besides, Shigeru Wanshu (2015) also pointed out how teachers should consider the problem, that is, the relationship between "morality" and "moral practice". Moreover, Shigeru Wan further indicated that "the special subject - morality" as the basis of every subjects, integrated learning, and special activities lies in the exhibition of moral implementation, for this is the ability consolidated by sense, emotion, and will.

(5) The implement of the sub-textbook- "our morality" and "mind note". Currently, putting "our morality" and "mind note" into practice and focusing on implementing the understanding of moral value. Making students realize their own way of existence, stress the points of moral teaching, discussion, and thinking, and develop the modern issues which are related to self to be the center of teaching. 
Ohara Ryuichi (2016b) pointed out that the "modern issues" of the current notes on the modified guidance and sustained development of the information moral society are listed. Moral education is based on the certain understanding of the moral values and discover oneself, implementing the learning by thinking in depth with multiple facets and points for the way of self-survival. Modern issues concerning the sustaining development of the society are not the center of the education. Problems surrounding the sustaining development of the society are the various problems, such as environment, poverty, and human rights. The developments of a sustainable society face a variety of problems, such as the environment, poverty, human rights, etc. These issues are about "respect for the rules", "fairness and social justice", "the loss of traction value and cultural", "international understanding, international goodwill", "the preciousness of life", "natural love", and so on. Based on these, the intentional, planned, and sustainable development of society were considered (Ryuichi, 2016b).

Besides, Hiroshi Sanuki (2015) pointed out that favoring of "Japanese principle" in the era of internationalization conveys the manifestation that only Japanese are making the efforts and therefore lacking the world principle and global principle.

\section{Research Design and Implement}

This research aims to understand the modern issues in the moral curriculum and how to construct the modern issue in these two sub-textbooks: "our morality" and "mind note". The research method focuses on the interviews with six Japanese experts and five elementary and middle school teachers, and the semi-structure interviews conducted.

This research are divided into four stages:

1. Preparation: (1) draft the topic; (2) conceive the research outline; and (3) draw the logical context.

2. Guideline: (1) decide the research topic; (2) embark on research plan; and (3) compile the outline of interview.

3. Formality: (1) interview; (2) classroom observation; and (3) content analysis.

4. Thesis writing: (1) document analysis; and (2) writing research thesis.

\section{Research Results and Discussion}

Based upon Japan's curriculum on international issues, moral education is to learn through doing specifically, through international community service and understanding different culture in global environment.

The main research result and discussion are as follows.

\section{Research Results}

International issue of "mind note" in the elementary school. In Japan, one-third of the courses for fifth and sixth graders are international issues. Therefore, elementary schools cultivate students' international view. 
Example 1:

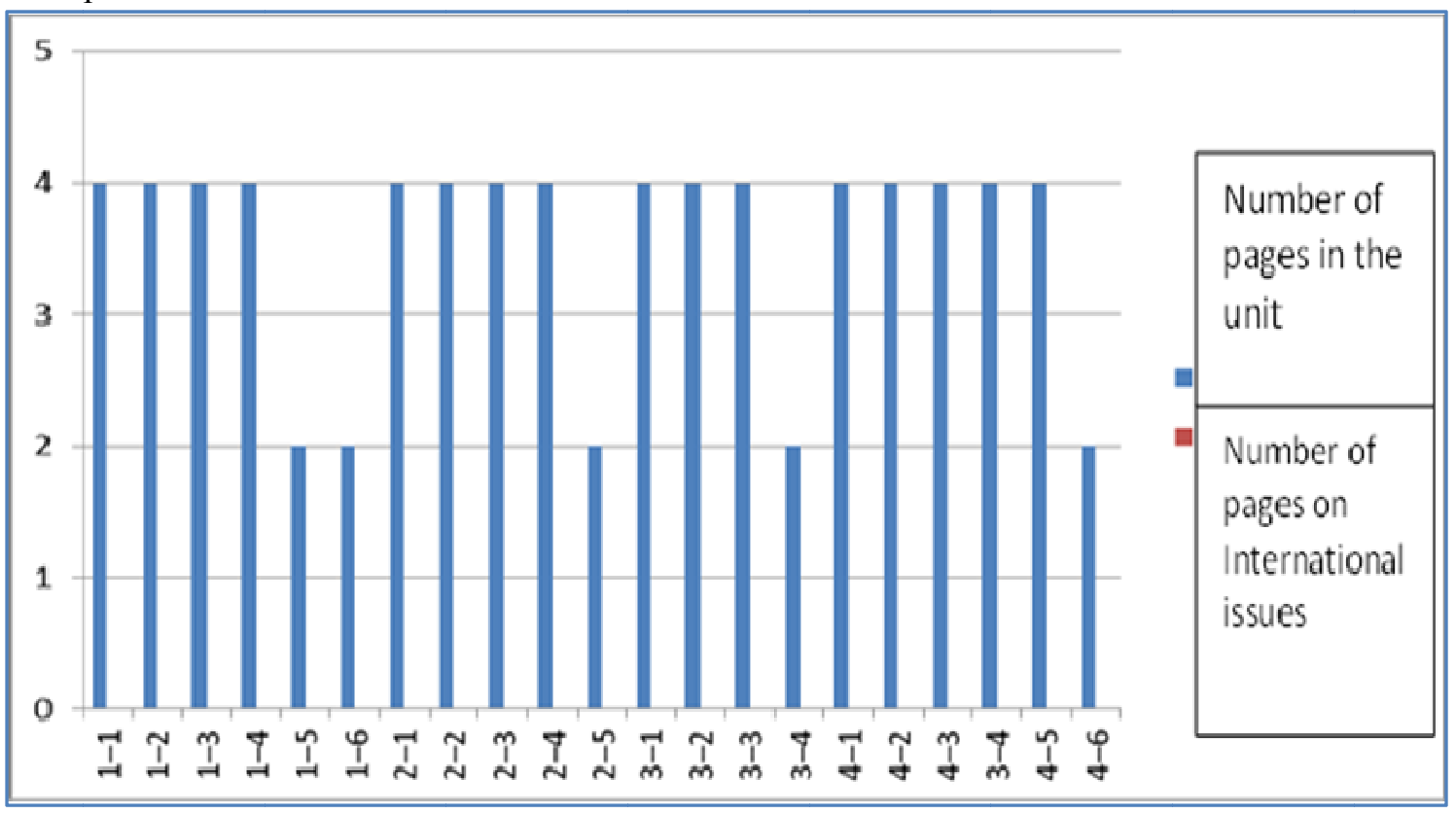

Figure 1. The statistical graph of unit material for first and second graders in elementary school.

From Figure 1, it can be seen that the focus of the moral curriculum of first and second graders is on the manners of daily life. Nothing concerning the "international issues" is provided.

Example 2:

\section{"Mind Note" for 1st and 2nd Graders}

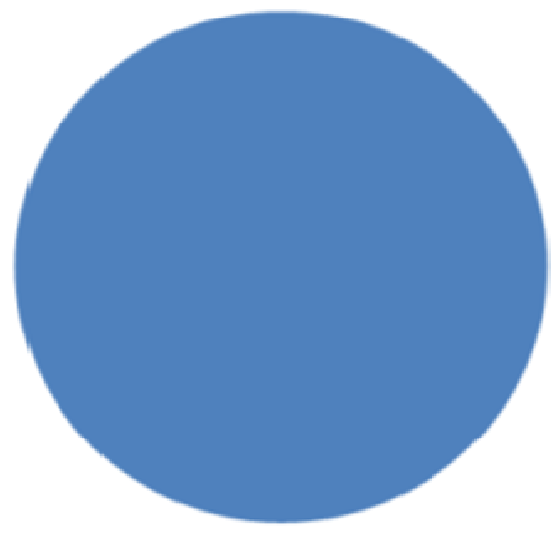

A total of 21 units not related to"international Issues"

Figure 2. The statistical graph of units which are related to "international issue" for 1st and 2nd graders in elementary school.

From Figure 2, the "international issues" related unit is zero, indicating that the Japanese Ministry of Education did not focus on the "international issues" when editing the "mind notes" for the 1st and 2nd graders. 
Example 3:

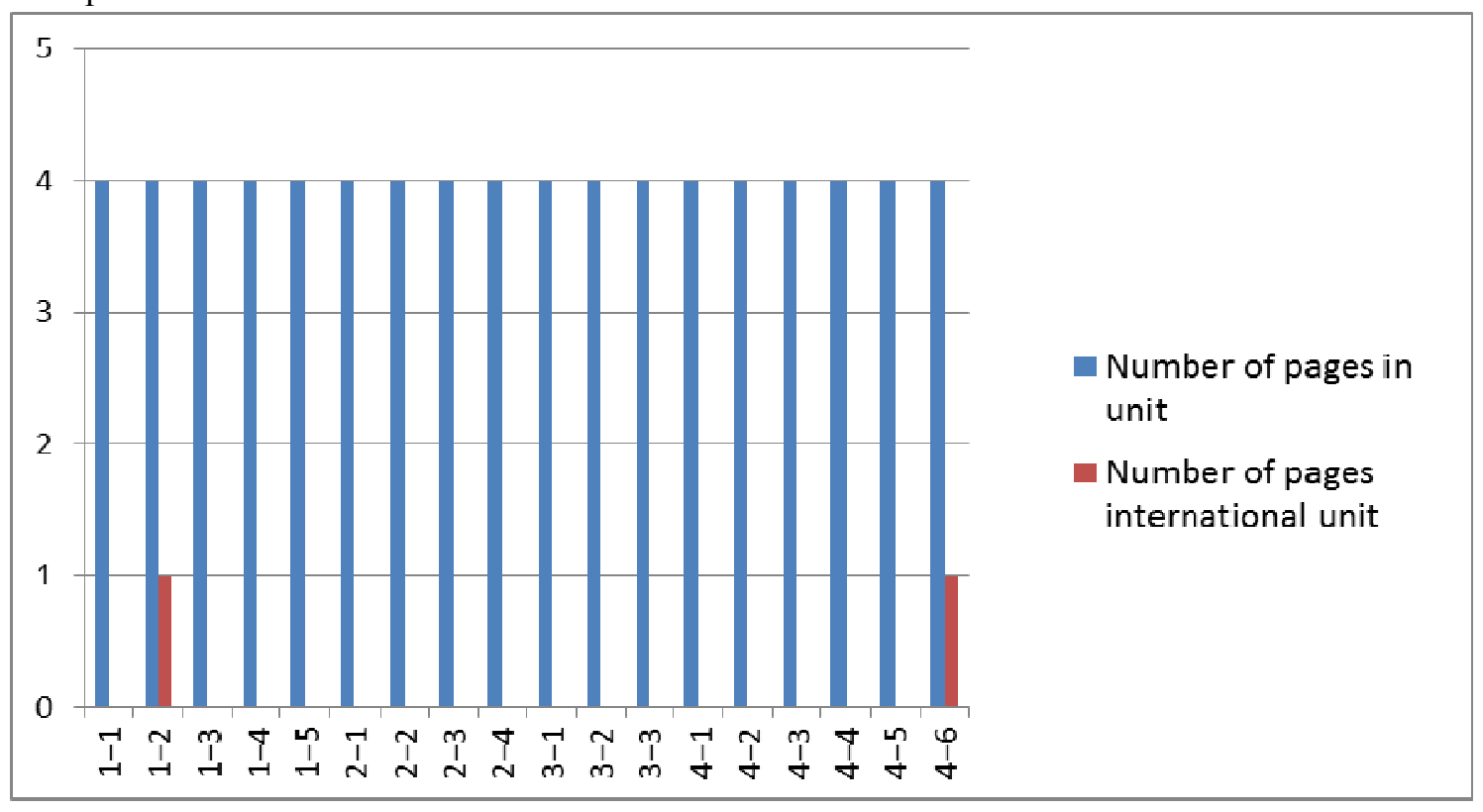

Figure 3. The statistical graph of unit material for3rd and 4th graders in elementary school.

From Figure 3, there are four main topics in the "mind note" for the 3rd and 4th graders of the elementary school. The 4th topic "living in good mood with everybody" has six subtopics, which constitutes the most number of subtopics, followed by the 1st topic "becoming the shining one" with five subtopics, 2nd topic "survival with people" with four subtopics, and 3rd topic of "contacting Life" with three and the least subtopics. Furthermore, the number of pages in the subtopics for the main topics in the 3rd and 4th graders is pretty consistent.

Example 4:

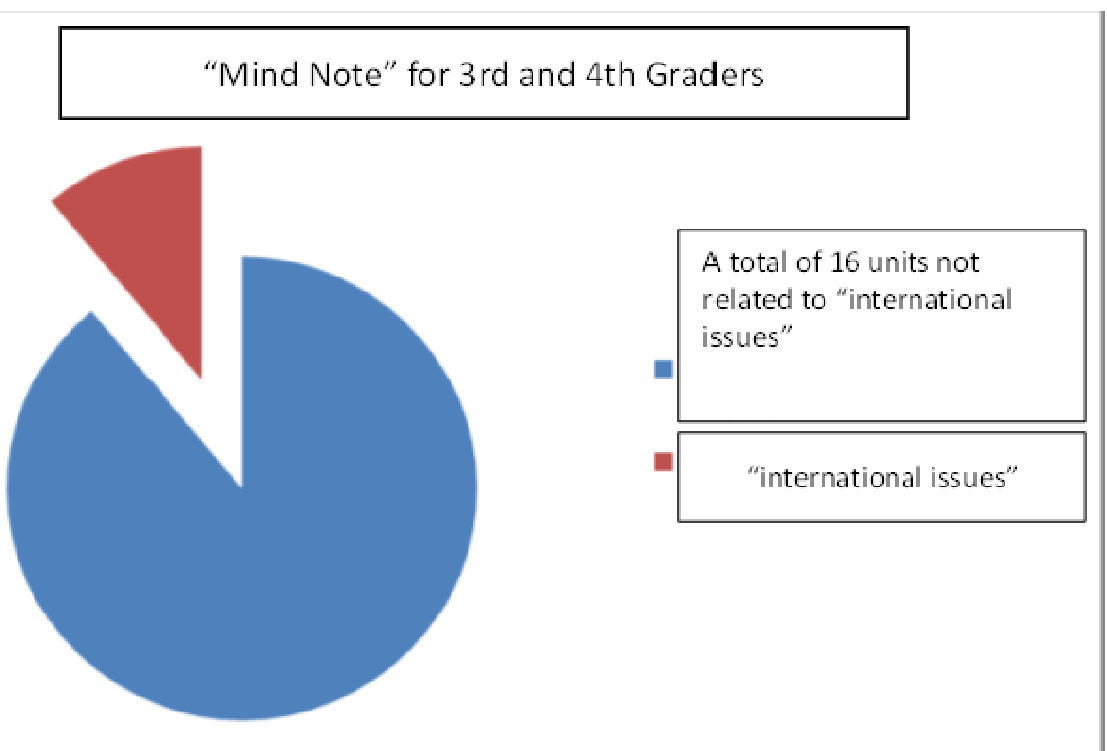

Figure 4. The statistical graph of units which are related to "international issue" for third and fourth graders in elementary school 
From Figure 4, it can be seen that knowing and understanding of "international issues" start to be included in the 3rd and 4th grades of the elementary school. "International issues" is now an essential subject in this era of globalization.

Example 5:

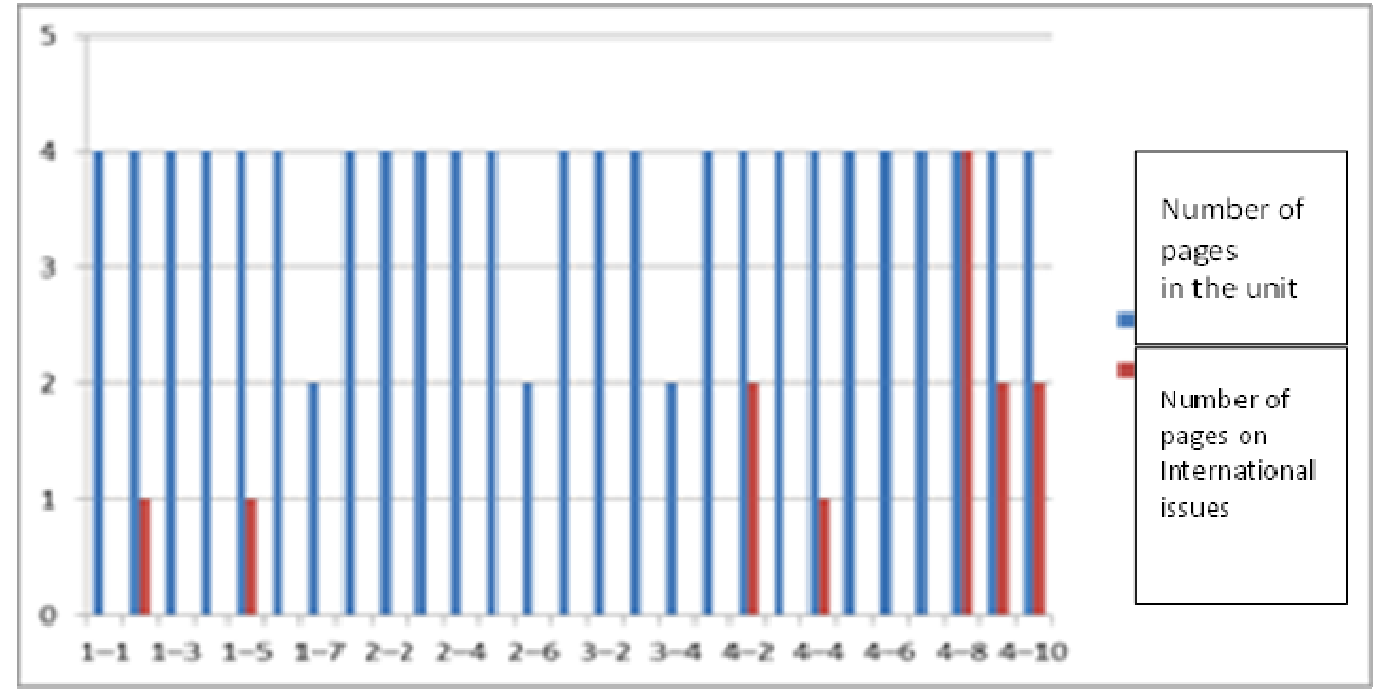

Figure 5. The statistical graph of unit material for 5th and 6th graders in elementary school.

From Figure 5, compared to the younger graders in the elementary school, the 5th and 6th graders have more focus on the "international issues".

Example 6:

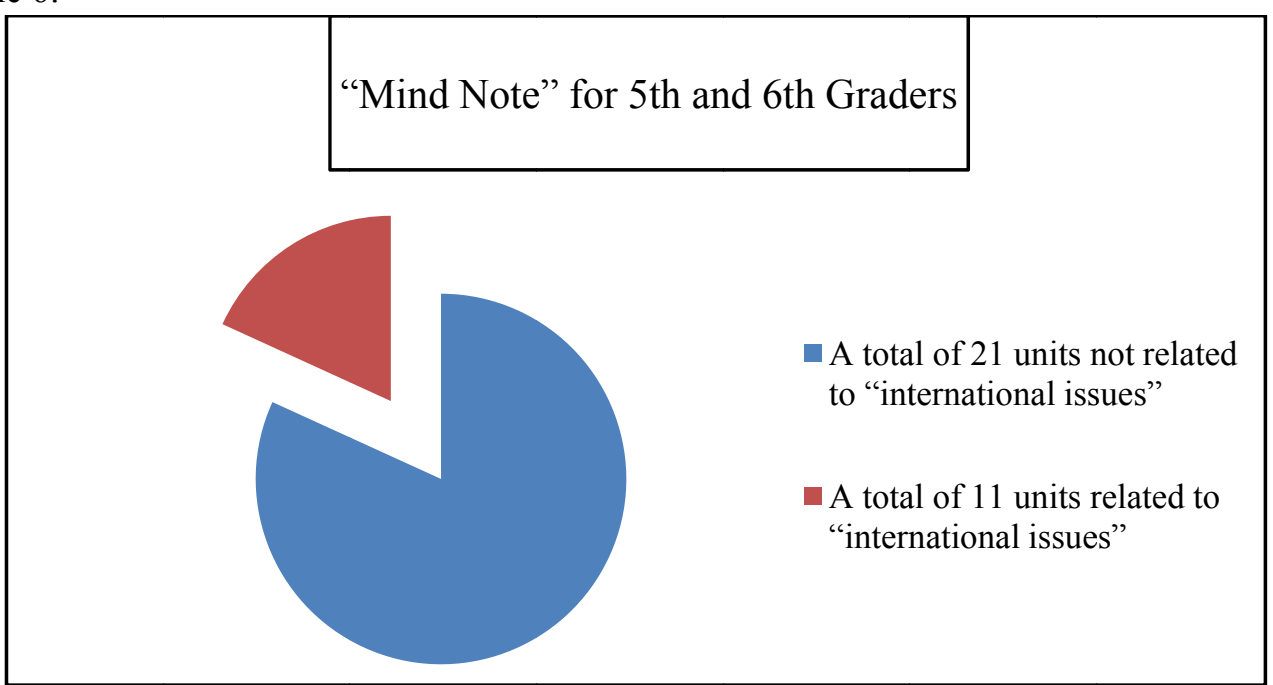

Figure 6. The statistical graph of units which are related to "international issue" for 5 th and 6th graders in elementary school.

From Figure 6, it can be seen that "international issue" is emphasized in the higher grades of the elementary school in this era of globalization.

International issue of "mind note" in the middle school. Based on the research analysis, the percentage of the international issue in the courses is about one-eighth. Compared with that in the elementary schools, the international issue is paid with less attention. 
Example 7:

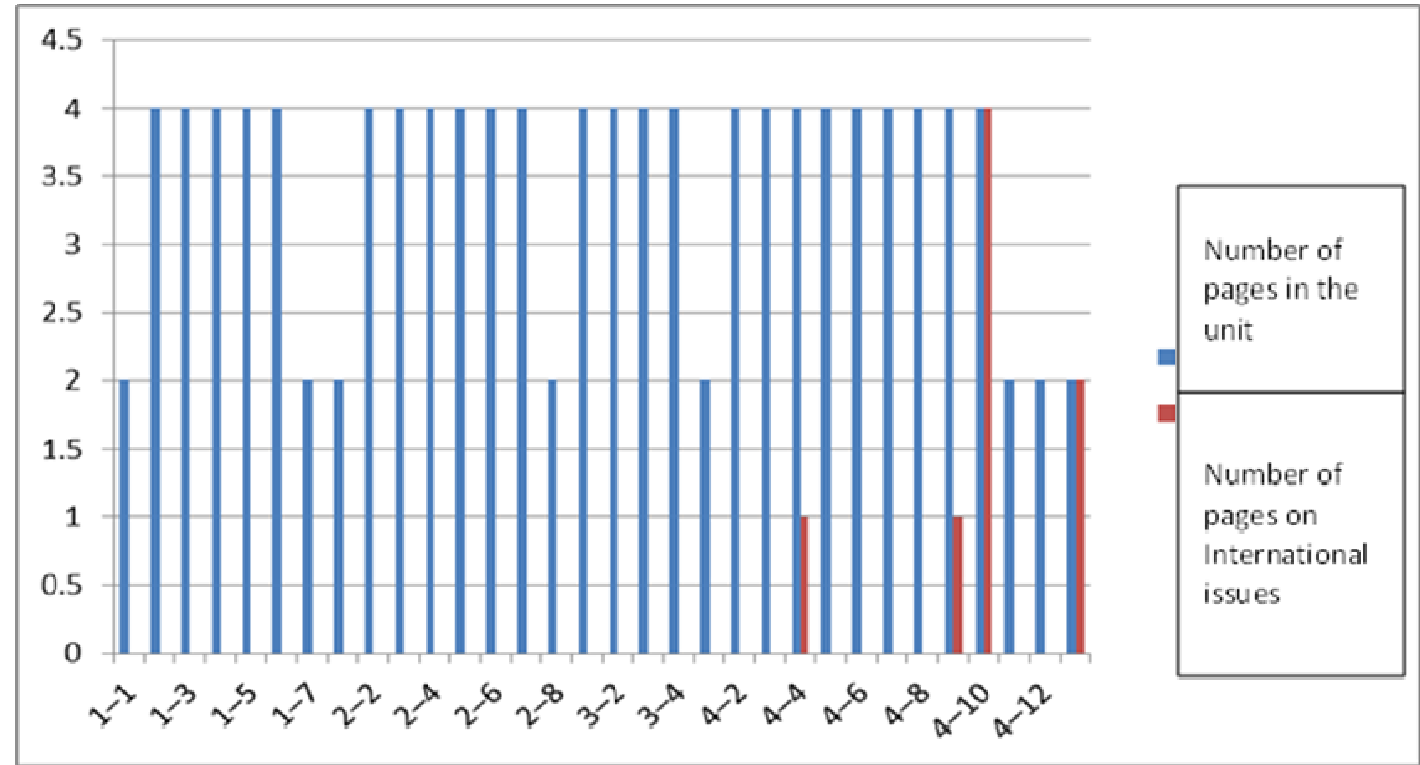

Figure 7. The statistical graph of unit material for first, second, and third graders in middle school.

From Figure 7, there is an increase on the unit pages emphasizing on the "international issues". There are four main topics in the "mind note" curriculum, among them, the 4th topic on "interaction with groups and society" has 12 subtopics, the most number of subtopics, followed by the 2nd topic on "interaction with others", where there are eight subtopics, the 1st topic on "surviving with people" has seven subtopics, and the 3rd topic on "interaction with nature and noble matters" has the least subtopics of four.

Example 8:

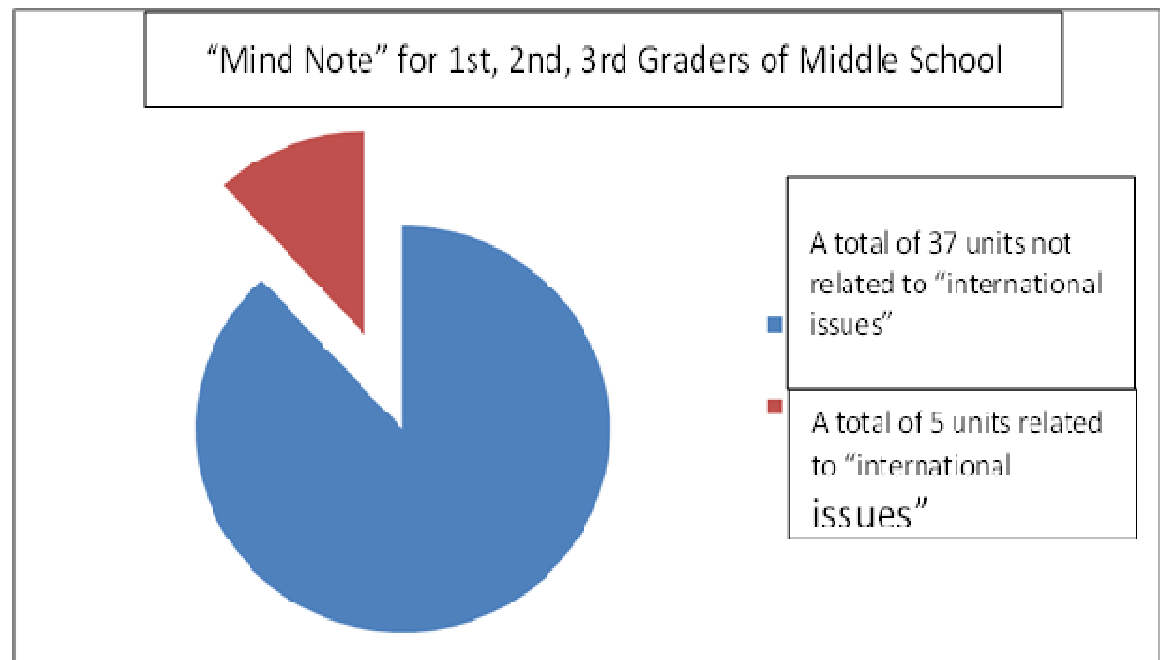

Figure 8. The statistical graph of units which are related to "international issue" for first, second and second graders in middle school.

From Figure 8, although there are units concerning the "international issues", in contrast to an obvious increase from the 5th and 6th graders, there is a decrease. Therefore, there is yet an emphasis on the international issues in the editing of "mind note" for middle school. 
International issues of "our morality" in the elementary school. In addition to deepen the realization of life attitude toward themselves and the etiquette of treating others, students cannot detach themselves from the world.

Example 9:

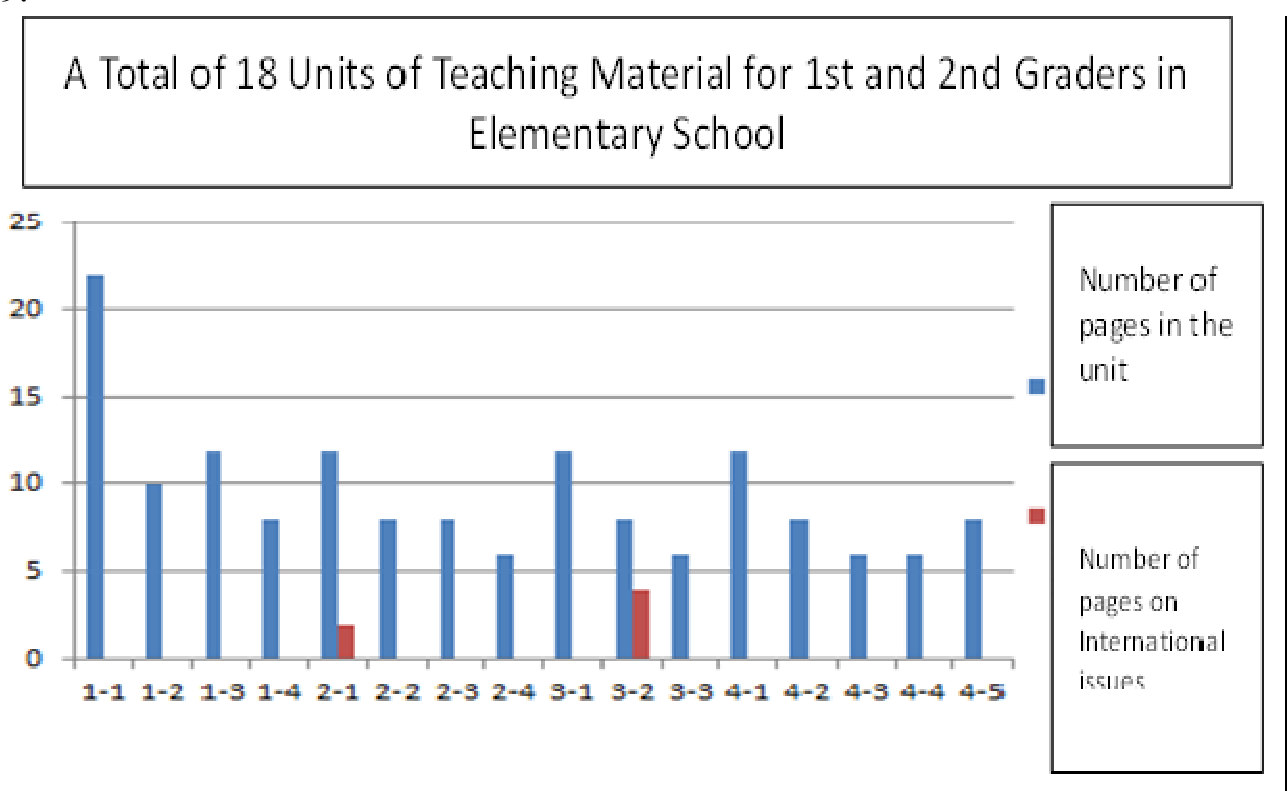

Figure 9. The statistical graph of unit material for first and second graders in elementary school.

From Figure 9, there are four main topics in "our morality", and there is an unit on "international issues" in the 2nd and the 3rd main topics.

Example 10:

A total of 18 units of teaching material for 1st and 2nd graders in elementary school

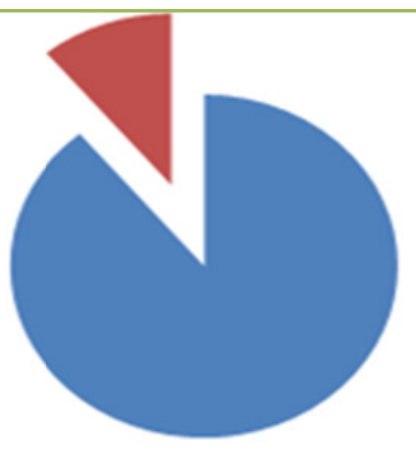

A total of 16 units not related to "international issues"

A total of 2 units related to "international issues"

Figure 10. In the teaching material "our morality", the statistical graph of units which are related to "international issue" for 1st and 2nd graders in elementary school.

From Figure 10, we can know that there are two units on the "international issues" in the "our morality" for the 1st and 2nd graders, revealing that international issues is the essential focus in this era of globalization. 
Example 11:

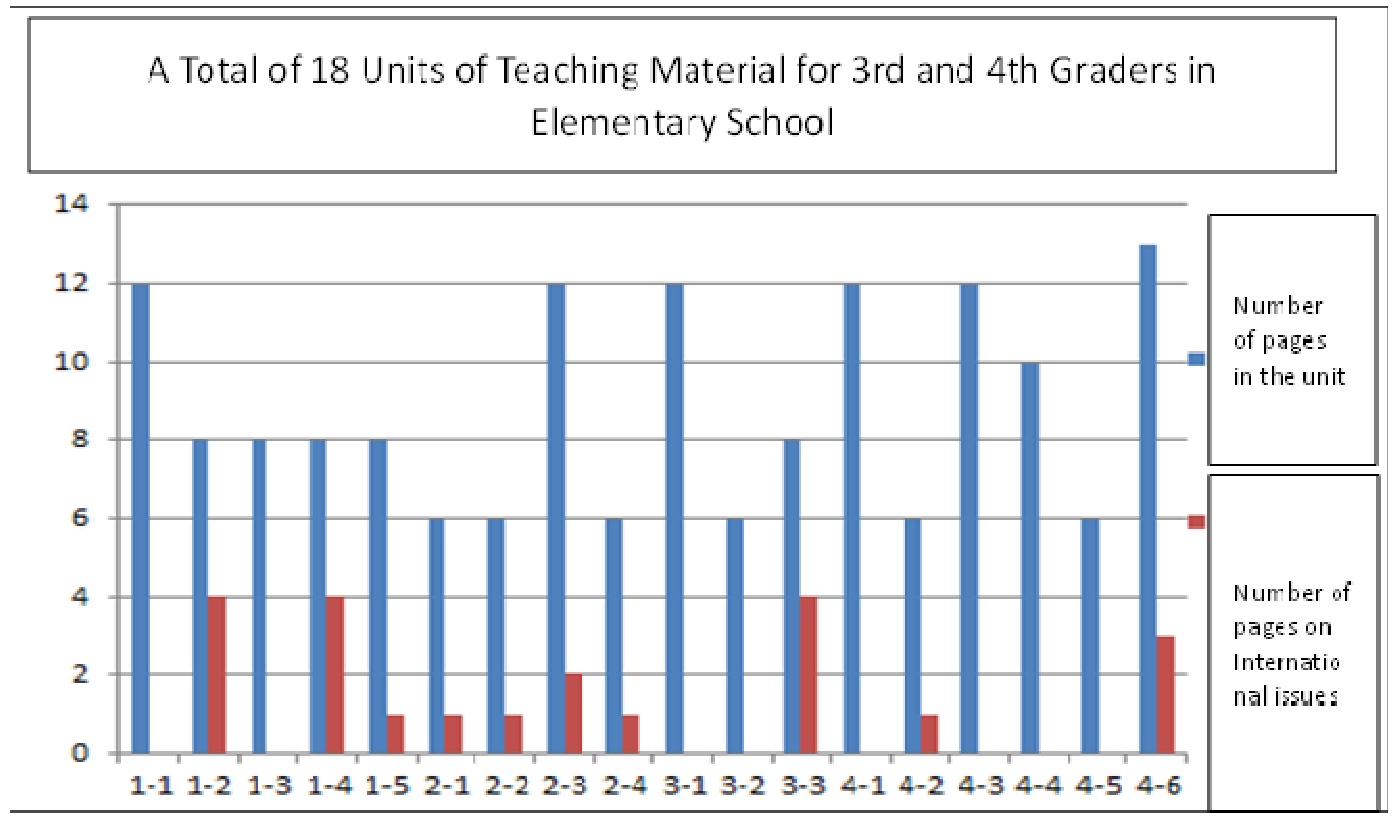

Figure11. The statistical graph of unit material for 3rd and 4th graders in elementary school.

From Figure 11, in the four main topics of the "our morality", the 2nd main topic has the most units on "international issues". Therefore, "our morality" for the 5th and 6th graders of elementary school has four main topics, and the 1st main topic "improving oneself" has the most subtopics that comprise the units on "international issues" with a total of five subtopics; which is followed by the 4th topic "interactions with everyone", having four subtopics comprising the units on international issues, and the 2 nd topic on "interaction with people" and the 3rd topic on "feel the life" have the least subtopics comprising only two units on international issues.

Example 12:

Figure 12. In the teaching material "our morality", the statistical graph of units which are related to "international issue" for 3rd and 4th graders in elementary school. 
From Figure 12, we can see that in the four main topics of the "our morality" for the 3rd and 4th graders, there are 10 units on international issues, which prove itself as the essential focus in this era of globalization.

Example 13:

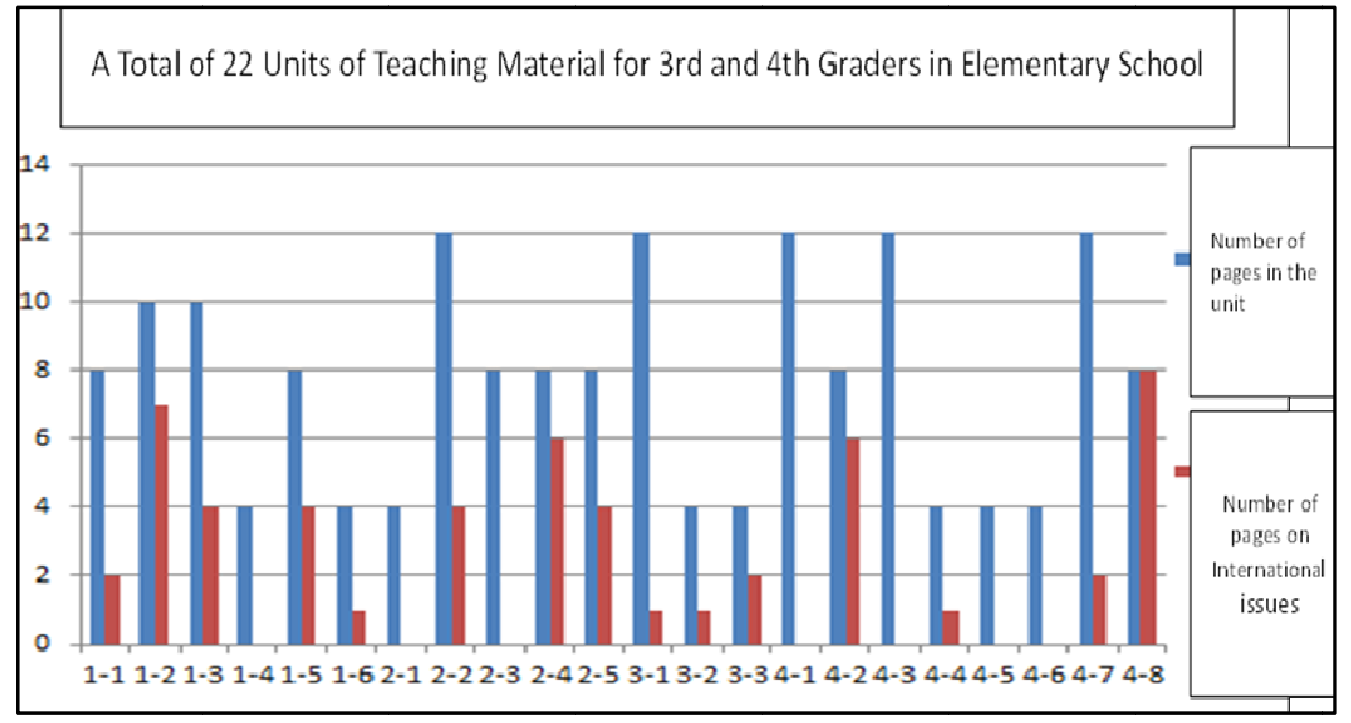

Figure 13. The statistical graph of unit material for 5th and 6th graders in elementary school.

From Figure 13, we know that there are four main topics in the "our morality" for 5th and 6th grades in the elementary school. The first main topic "improving oneself" has five subtopics that comprise the units on "international issues" and has the highest number of units, followed by the 4th main topic "interaction with everyone" with four subtopics that comprise the units on "international issues", and the 2nd main topic on "Interaction with people" and 3rd main topic on "feel the life" have two subtopics, the least of all, that comprises units on international issues.

Example 14:

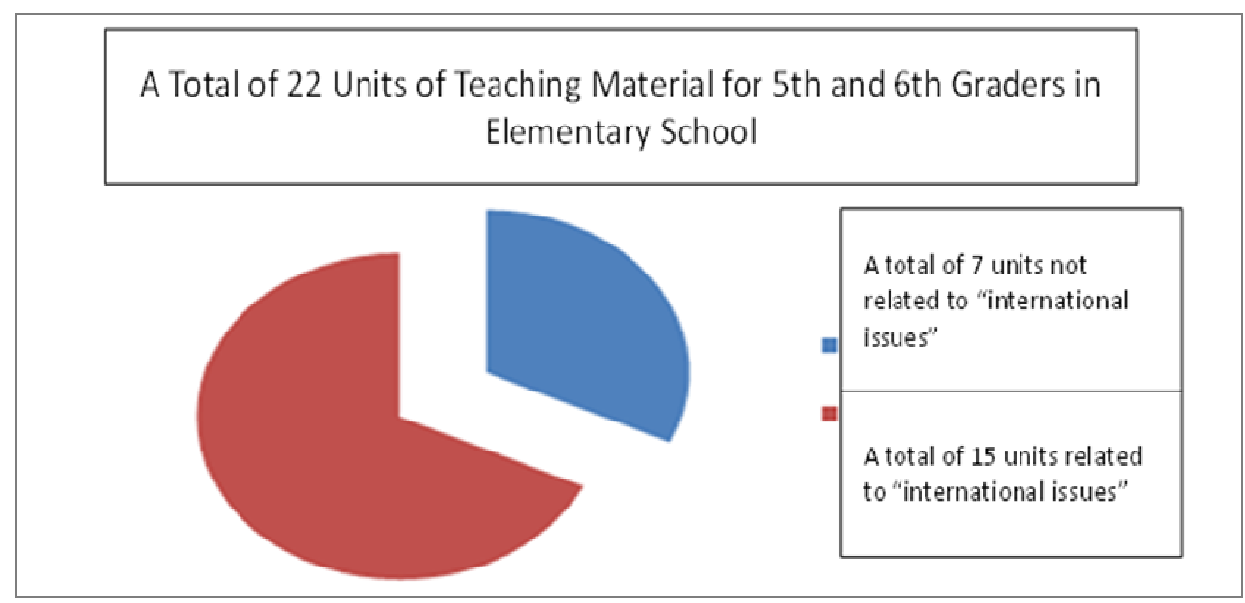

Figure 14. In the teaching material "our morality", the statistical graph of units which are related to "international issue" for 5th and 6th graders in elementary school.

From Figure 14, we can see that in the four main topics of the "our morality" for the 5th and 6th graders, there are 10 units on international issues, which prove itself as the essential focus in this era of globalization. 
International issue of "our morality" in the middle school. The teaching materials of Japanese middle school are also based on the ones of elementary school and are discussed in details. In addition to caring about the goals they establish and forming a positive attitude toward life, students also need to understand the connection with others, pond over what responsibility they have in the groups, and care about the situations of other countries. They need to devote themselves in making contributions to the nation and the world.

Example 15:

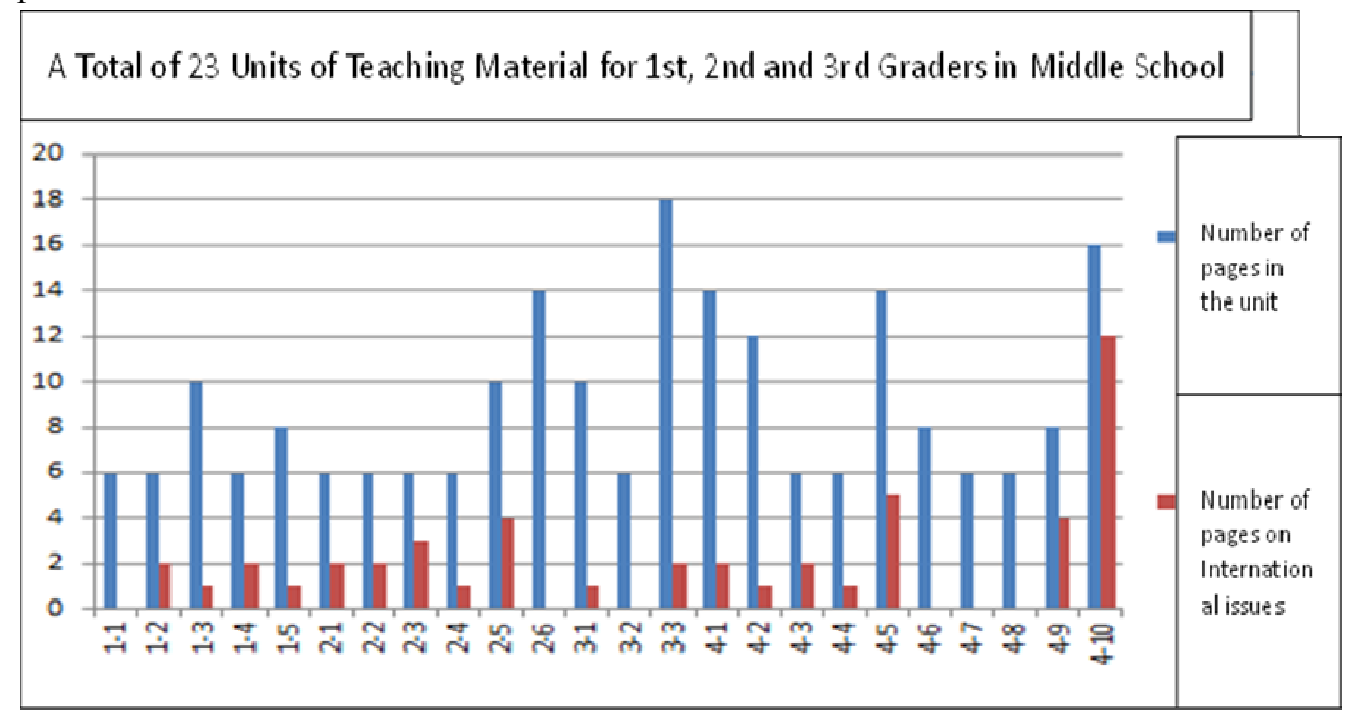

Figure 15. The statistical graph of unit material for first, second and third graders in middle school.

From Figure 14, there are four main topics in "our morality". The 4th main topic on "being one of the society" has seven subtopics and has the highest number of units on international issues, followed by the 2nd main topic "mutual support of others" has five subtopics that comprise the units on international issues, and the 1 st main topic on "interaction with everyone" has four subtopics that comprise the international issues, and the 3rd main topic on "feel the life" has two subtopics and the least that comprises the units on international issues.

Example 16:

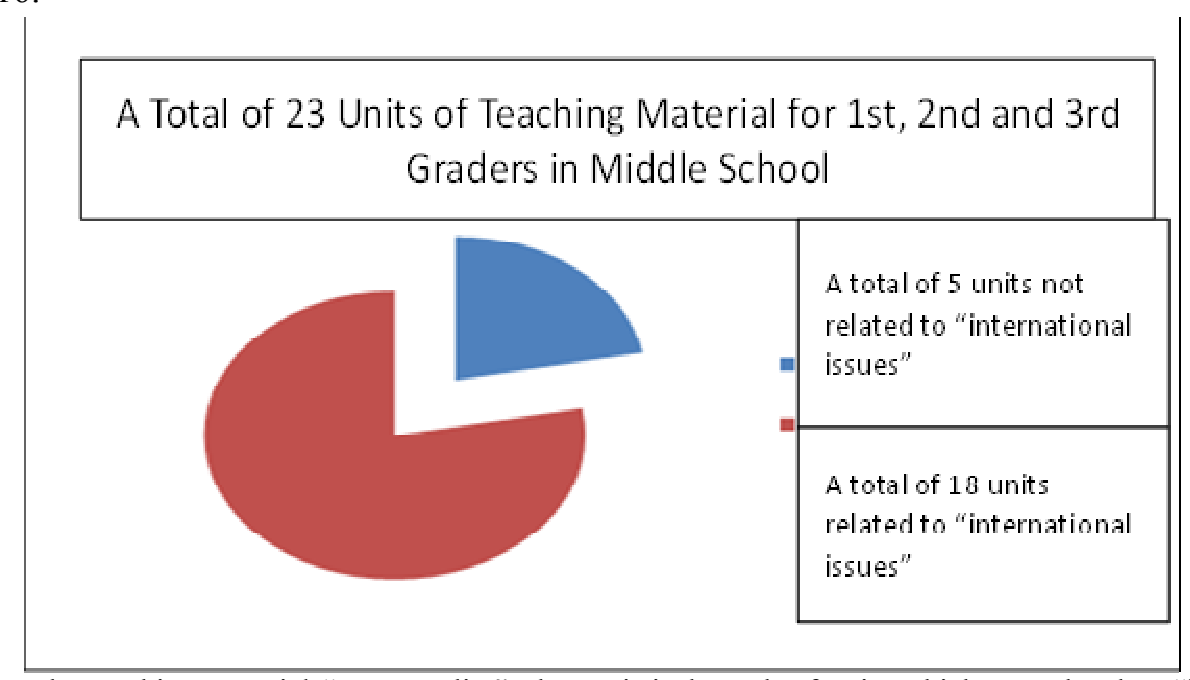

Figure 16. In the teaching material "our morality", the statistical graph of units which are related to "international issue" for first, second, and third graders in middle school. 
From Figure 16, we can see that there are a total of 18 units out of 23 in "our morality" for the 1st , 2nd, and 3rd graders of middle school that involve "international issues". That is a percentage of 18/23 and it can be seen that international issues is the essential focus in this era of globalization.

\section{Discussion}

In the interviews, scholars mentioned that in the future, Japanese special subject "morality", could deepen Japanese self-awareness and make contributions to the whole world. In the Japanese earthquake, especially, Japan has received assistance from all over the world. It makes students realize that as a member of the global village, they have to make contributions to the world.

In summary, Japan's international issues is to develop the international consciousness to make moral judgment or decisions, and to organize the contents of modern issue including "environment", "understanding of different culture", "life ethics", "regional society", and "information", so that students understand many fundamental moral rules of international culture at early age and are capable of gaining progressively greater insights into international issues as they develop.

\section{Conclusions and Suggestions}

An important part of social development is to develop the international ability to make moral judgments or decisions, and schools should teach moral values. Thus, teachers pay more attention to students' moral development. The different theories of moral development are based on rather different definitions of the central issues of international morality. But teachers must integrate different modern issues of moral development and develop international programs to foster "honesty", "service", "self-control", "friendliness", "democratic virtues", and "other moral virtues" in the international consciousness of all students. The main findings are as follows.

\section{Conclusions}

(1) The reason why Japanese moral education becomes a special subject is because the government hopes to develop students' moral sprit in the elementary school and middle school.

(2) The reason why Japanese moral education becomes a special subject is because the government hopes to raise teachers' awareness of moral education.

(3) With the time, adding of "modern issue" to international issue.

(4) The percentage of moral issue is limited in one semester.

(5) Editing textbook would be beneficial for teachers to make good use of it.

In summary, moral education aims to increase international ability to use and understand the rules of different culture, cultural expectations, and particularly, cultural meanings, so that the teachers and administrators provide the conditions for positive growth rather than suggest specific instructional strategies and administrational policy.

\section{Suggestions}

According to the findings mentioned above, 11 suggestions are offered concerning educational administration, schools, teachers, and further research.

(1) For educational administration:

a. We should put emphasis on good methods to improve teaching;

b. It can make students to think and discuss their learning; 
c. Japan incorporates the modern items ("environment", "understanding of different culture", "life ethics", "regional society", and "information") into curriculum and it will be helpful.

(2) For schools:

a. Japanese experience can be put into our teaching; it will raise the teaching efficiency.

b. Focus on observation learning, dialogue and thinking to improve teachers' professional growth.

(3) For teachers:

a. Teachers should have international vision and students should think about modern issue (international vision);

b. Having moral subject systematically connecting with other curriculum and activities;

c. Developing students' good view of morality, thinking of the role of a citizen in the globe, experiencing the style of global village, and pursuing international understanding, international devotion, international friendship.

(4) Further research:

a. The research tools might have to be refined;

b. The methodology might have to be variegated;

c. The variables might have to conform to the law of causality;

d. The findings might have to be verified and followed up.

\section{References}

Akahori, H. (2016). Improvement and enrichment of contents for "special subject morality". Primary education materials. Department of Education Department, 5, 2-5.

Hayashi, Y. (2015). Subject of morality and its pedagogical background. School Education Research, 30, 38-49.

Hiroshi, S. (2015). How to promote education of morality-Criticism of "moral education" of morality. Tokyo: New Japan Publishing House.

Huang, W. S. (2001). A theoretical study of moral development in adolescence and its educational application. Educational Review, 17, 356.

Kaizuka, S. (2016). Postwar moral education and intercultural understanding education-Focusing on the subject of "special subject morality". Japanese Association of Understanding Education, 22, 40-49.

Kiichi, E. (2016). History of Japanese moral education-From recent to modern. Minerva Shobo.

MEXT. (2009a). Mind note (First and second graders, elementary school). Tokyo: MEXT.

MEXT. (2009b). Mind note (Third and fourth graders, elementary school). Tokyo: MEXT.

MEXT. (2009c). Mind note (Fifth and sixth graders, elementary school). Tokyo: MEXT.

MEXT. (2009d). Mind note (Middle school). Tokyo: MEXT.

MEXT. (2014 a). Our morality (Fifth and sixth graders, elementary school). Tokyo: Koshizudo Akatsuki.

MEXT. (2014 b). Our morality (Middle school). Tokyo: Koshizudo Akatsuki.

MEXT. (2014c). Our morality (First and second graders, elementary school). Tokyo: Bunkado.

MEXT. (2014d). Our morality (Third and fourth graders, elementary school). Tokyo: Educational Publishing.

MEXT. (2015). Drastic improvement of moral education implementation. Retrieved from www.u-gakugei.ac.jp/.../27.6.../k01 syotoutyutounokyouikukateikijyun on 2016/10/03

MEXT. (2016). Improvement of necessary guidelines and guidelines for kindergarten, elementary school, junior high school, senior high school and special support school etc. and necessary measures etc. (Reports, Chuo Gakkai No. 197). Retrieved from http://www.mext.go.jp/b_menu/shingi/chukyo/chukyo0/toushin/1380731.htm

MEXT. (2017). Kindergarten, elementary and middle schools: Points of revision of the guidelines for teaching. Retrieved from http://www.mext.go.jp/a_menu/shotou/new-cs/1384662.htm on 2017/08/21

Nagata, S. (2016a). Fostering supple mind-Aiming at transition to special subject morality. From Professor Shigeo Nagata's speech, Tokyo National University of Fine Arts and Sciences. 
Nagata, S. (2016b). Moral lesson skill up seminar-Development of teaching method required for moral lesson of new era-How to create high quality and vigorous lesson. Tokyo: Tokyo Gakugei University Moral Education Research Group.

Nishino, M. (1994). International understanding and moral education after the war. In Y. Oda (Ed.), International Understanding Education and Practice of Education, Emmenty Publishing.

Nishino, M. (2013). Thinking about the moral class in the global era. In Y. Oshiya, \& R. Yanaginuma (Eds.), The era of moral came!: Recommendations for teaching moral subjects (pp. 21-26). Tokyo: Educational Publishing.

Oshiya, Y. (2013). What is the philosophy and purpose of morality's "subject"? In Y. Oshiya, \& R. Yanaginuma (Eds.), The era of moral came!: Recommendations for teaching moral subjects (pp. 2-10). Tokyo: Educational Publishing.

Otsu, T. (2010). Moral and global citizenship education in Japan, England, and France. Research Bulletin of Education, 5, 53-60.

Robert, V. K., \& Rita, W. N. (1993). Developmental psychology (p. 353). Prentice Hall.

Ryuichi, O. (2016a). Promotion of moral education toward the implementation of "special subject-moral". Primary Education, 5 , 12-15.

Ryuichi, O. (2016b). Improvement of contents of Crade 1 and Crade 2 and their correspondence. Primary Education Material. Ministry of Education, Department of Education, 5, 2-5.

Shishido, S. (2016). International understanding and moral education after disasters-International understanding education and the form of moral education after disaspectable from the Great East Japan Earthquake. Japanese Association of Understanding Education, 22, 78-84.

The Japan Foundation for Children Education Promotion. (2016). 70 years history of school education after the war. Tokyo: Elementary School Pavilion Corporation.

Tokyo Gakugei University. (2012). “Integrated Moral Education Scheme”. In Promotion Headquarter (Ed.), Small on moral education: Survey for teachers of junior high school - focusing on efforts to moral time (Survey report).

Wanshu, S. (2015). The issue of history of moral "specialized curriculum"-the development of education in modern Japan and moral education after the war. Tokyo: Kitagi Publication.

Yoshida, T., Tanaka, M., \& Ikkosodeo. (2011). Formation and problem of moral education-from "heart" to "tsunagari". Tokyo: The Academic Book Company. 